\title{
An epidemiological study of occupational bladder tumours in the dye industry of Japan
}

\author{
KENZABURO TSUCHIYA', TOSHITERU OKUBO', and SUMIKO ISHIZU² \\ Keio University School of Medicine', and Tokyo Women's Medical College ${ }^{2}$
}

Tsuchiya, K., Okubo, T., and Ishizu, S. (1975). British Journal of Industrial Medicine, 32, 203-209. An epidemiological study of occupational bladder tumours in the dye industry of Japan. This report studies 100 cases of occupational bladder cancer which were reported between 1949 and 1970 by large companies producing dye. It is estimated that in fact a great many more than 100 cases may have developed during the 56 years from 1914 to 1970 , as this period corresponds with the beginning of dye production to the termination of benzidine and $\beta$-naphthylamine manufacture in Japan.

New cases of occupational bladder tumour should diminish significantly in the future in Japan on account of the prohibition of the production of $\beta$-naphthylamine and benzidine. However, it is important to follow-up continuously workers who have been exposed to these amines.

In Japan no cases of occupational bladder tumours from the rubber industry have been reported. It is emphasized that prospective epidemiological studies are required not only in the rubber industry but also in other industries where amines may constitute an occupational hazard.

A synthetic dye called alizarin, which is a derivative of anthracene, was first produced in Japan in 1914. Since that time the dye industry has developed rapidly, and by 1938 Japan had become the fourth largest dye-producing country in the world. In the year 1938 her total production of dyes from coal represented $14 \%$ of the entire world production (Hosoda, 1957). Dye production started decreasing after 1938 and eventually became negligible because of the second world war. However, production was resumed after the war and had reached the pre-war level by 1953. In the following years the output of benzidine increased considerably, partly because of increasing demands for export to mainland China. The working conditions at that time were very poor and cases of workers with acute cystitis or haematuria caused by heavy exposure to benzidine were frequently reported (Ōida, 1957).

During the 30-year period after dye production began, mainly before the second world war, only three reports of occupational bladder tumour were published. The first report, concerning occupational bladder tumour in a dyestuffs manufacturing plant in Japan was made by Nishimura (1940) who found four cases. In the same year, Nagayo and Kinoshita (1940) also reported several cases of occupational bladder tumour. Takahashi et al. (1945) reported bladder cancer in a painter who always licked his brush which had a dyestuff containing aniline and alizarin on it. During the ten years following the second world war the number of cases gradually increased, but no reports or records of a case during that period have been found, possibly because of death, transfer of job, migration, etc. caused by the second world war. It is believed, however, that an appreciable number of cases might have occurred in and around the war years.

In 1948, occupational bladder tumours first became a focus of social concern as a health problem among industrial workers, and a committee ap- 
pointed by the Ministry of Trade and Industry investigated the problem in the dyestuffs industries.

Since 1951 there have been a number of reports of individual patients with an occupational bladder tumour, but no review or report has been made on the overall situation of occupational bladder tumour in the dye industry in Japan, except for those by Shiki (1970), Tsuchiya (1969), Tsuji et al. (1961). However, these reports do not necessarily cover all the cases; most probably they cover only a portion of the total number. It is also suspected that their reports may have partially overlapped.

In 1955, which may be the critical year in terms of improvement of the working conditions in the dye industry, the Ministry of Labour, the Japan Dyestuff Industry Association, and others, took steps to improve process control and workers' health care in the industry. In 1961 the Papanicolaou (1947) method of cytological examination of urine to detect early signs of tumours, began to be widely used in the dye stuffs and related industries. Furthermore, in 1971 the production and use of benzidine were prohibited by law.

In our study we have attempted to review the overall situation of the problem in Japan, to estimate its magnitude, and present an epidemiological picture of the bladder tumour problem which has never been clearly outlined.

\section{Method of study}

One of the authors of this paper (SI), has been a consultant since 1950 for the Ad Hoc Committee on Industrial Hygiene of the Japan Dyestuff Industry Association. At the end of 1969, 13 large companies belonging to this association which employs nearly $90 \%$ of the dye manufacturing workers were obliged to submit the records of cases of bladder tumour kept by each company according to the Labour Standard Law. The records included name, date of birth, sex, address (including permanent address by $k o s e k i$, a family registration system), date of employment, pre-employment history, period of exposure to aromatic amine carcinogens (start and termination dates), name of aromatic amine, results of Papanicolaou tests and other medical findings (histology, cystoscopy, etc.), date of retirement, and date of death. By the end of 1970, Ishizu had received 100 forms completed by physicians based on hospital records and submitted to the Japanese Dyestuff Industry Association.

In addition to the study of case reports, all of the above companies were asked to submit a report by the end of 1970 regarding the following items: total number of employees, age, sex, number of workers who had been exposed to carcinogenic aromatic amines as of December 1969 , number of exposed workers who had retired during the period 1947 to 1969 , and date of termination of the use of carcinogenic substances. Papanicolaou tests have been carried out by Ishizu since 1962, covering all the exposed workers in those factories. All efforts were made to detect cases among retired workers.

\section{Results}

In this paper only significant results are reported. Table 1 shows the total number of workers exposed to carcinogenic amines in the past or still exposed at December 1969. A total of 1787 workers had been exposed to such amines excluding the retired workers, although most companies had ceased the production of $\beta$-naphthylamine and benzidine by that date. Of these, only nine manufacturing workers, four workers using the dye, and eight who were only indirectly associated (for example, those working in repairs, transport, etc.) from company $E$ were still exposed to $\beta$-naphthylamine at that date. During the 23-year period from 1947 to 1969, 737 workers had retired; of these workers, 223 had handled benzidine and 196 had been engaged in the production of benzidine; in the case of $\beta$-naphthylamine, the figures for handling and production were 108 and 62 respectively.

A total of 1450 workers, including available retired workers, were offered the Papanicolaou test during the year 1969. Table 2 shows the results of the test. As shown in the table, the highest positive rates (grade III or higher) were observed (10-11\%) among the workers who had been engaged in the production of $\beta$-naphthylamine. Among those workers with grade III or higher, seven cases of bladder tumour were confirmed by cystoscopy.

In Fig. 1, 100 cases are classified by calendar year in terms of the year in which the diagnosis of bladder tumour was first made. It should be noted that only a few cases were observed before 1955, most probably because of the long latent period of the disease. As shown in Fig. 2, most of the workers entered work after 1945, but some of them started to work between 1935 and 1940 because, as mentioned in the introduction, Japan is $b$ relative newcomer to this industry.

With regard to the age distribution of the 100 cases, as shown in Table 3, the average age seems to be much younger than that of the general population. Ichikawa (1958) reported $24.1 \%$ cases of bladder tumour in persons of 49 years or younger and $75 \%$ in persons 50 years or older out of 1906 cases, although the population at risk may not be the same in respect of age. It should also be pointed out that older retired workers with tumours may have escaped notice.

Although we could not detect all the cases among the retired workers, we made a rough estimation of incidence, as shown in Table 4. As already shown in Table 2, higher incidences among workers involved in the production of either benzidine or $\beta$-naphthylamine are observed than among those workers who just handle the substances. However, since we could not be sure that all the information had been gathered, the difference in the incidences 
TABLE 1

No. of Workers Exposed to Aromatic Amines by Factory (A-O) AS of 1969

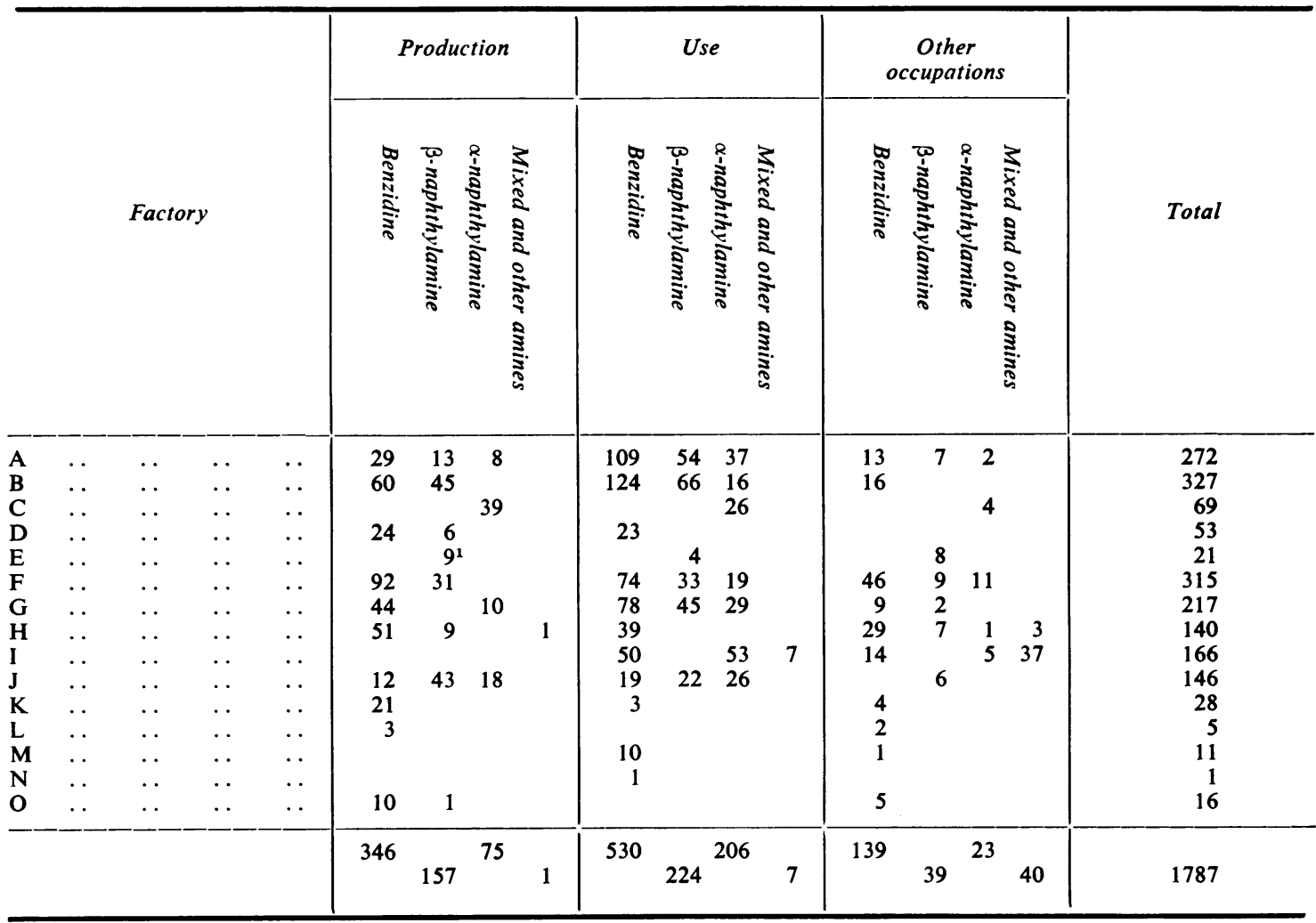

${ }^{1}$ All the factories except $E$ had stopped production and use of $\beta$-naphthylamine before December 1969

TABLE 2

Number of Examinees Including Retired Workers and Results of Papanicolaou Test PERFORMED IN 1969

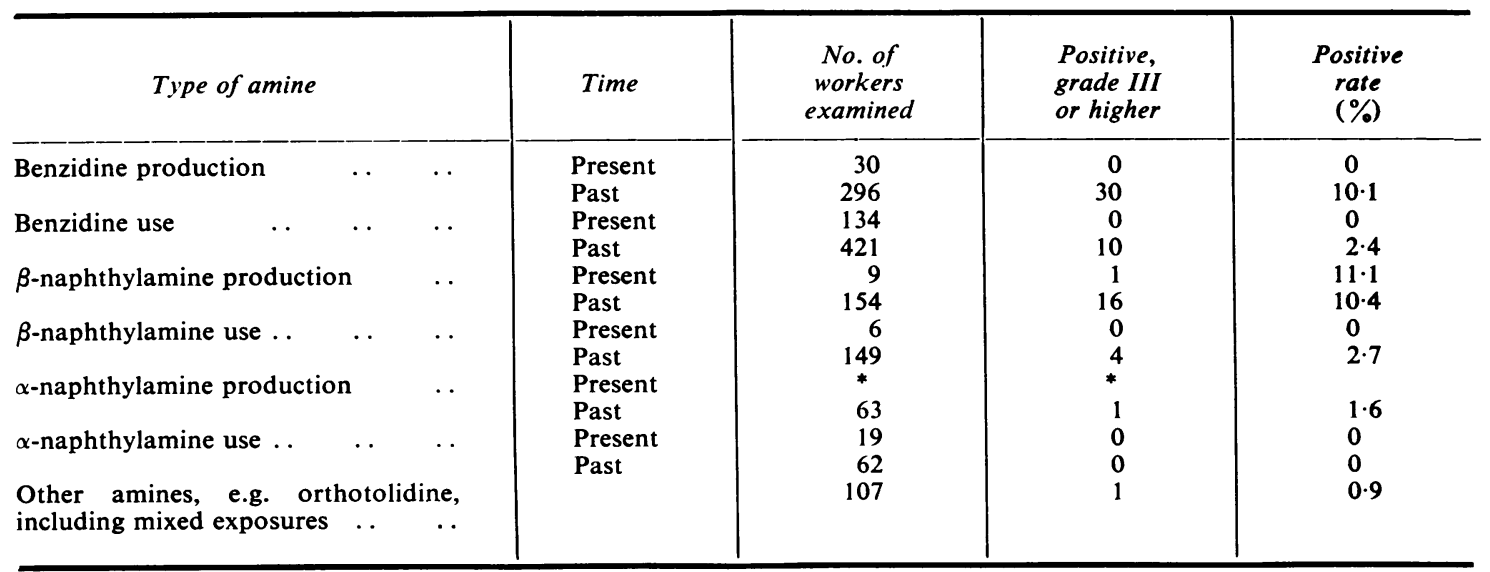

*In 1969 those companies in the study did not produce $\alpha$-naphthylamine 


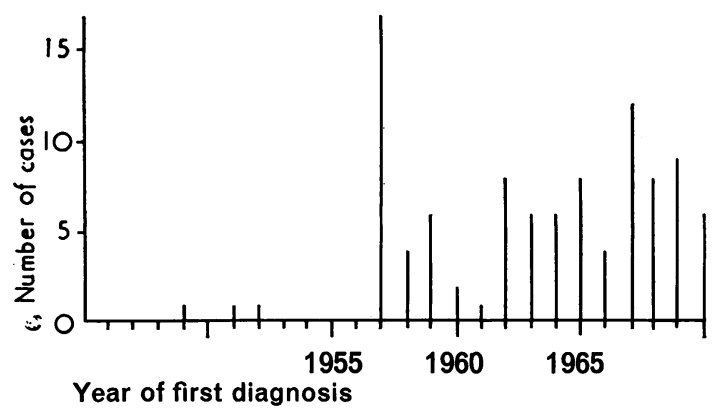

FIG. 1. New cases of bladder tumour by year.

between benzidine and $\beta$-naphthylamine may not necessarily be valid.

Sites of the tumours, classified by surviving and fatal cases, are shown in Table 5 . About $15 \%$ of the cases developed tumours in the upper urinary tract, a proportion obviously higher than those reported by other investigators. Scott (1962) reported that cases of tumour of the upper urinary tract, such as the pelvis of the kidney and the ureter, have been increasing in recent years because of the

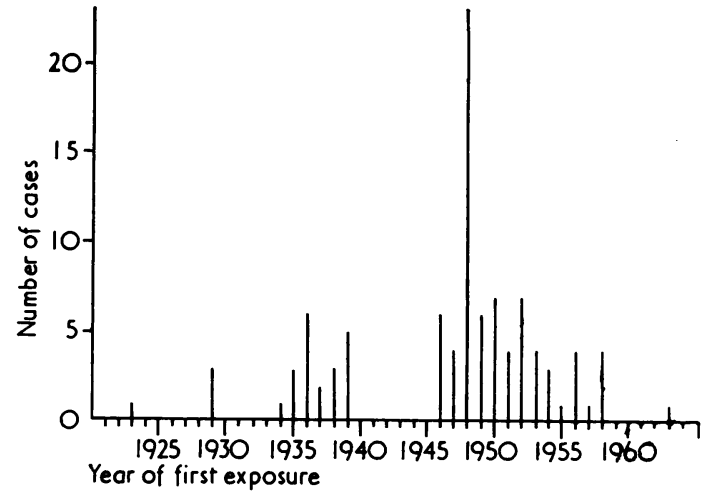

FIS. 2. Number of cases by year of first exposure.

prolonged period of survival. In addition to this, however, we believe that the improvement of diagnostic techniques may have contributed to the discovery of tumours in the upper urinary tract. It was noted that eight cases out of 100 developed tumour or tumours confined to the upper urinary tract and did not involve the bladder.

TABLE 3

Distribution of 100 Cases of Occupational Bladder Tumour by Age and Type of Amine

\begin{tabular}{|c|c|c|c|c|c|c|}
\hline \multicolumn{3}{|c|}{ Age } & $\beta$-naphthylamine & Benzidine & $\begin{array}{c}\text { Mixed } \\
\text { exposure } \\
\text { and/or } \\
\text { other amines }\end{array}$ & Total \\
\hline \multicolumn{3}{|c|}{$\begin{array}{l}-29 \\
30-34 \\
35-39 \\
40-44 \\
45-49 \\
50-54 \\
55-59 \\
60-\end{array}$} & $\begin{array}{l}2 \\
1 \\
2 \\
5(1) \\
4 \\
1 \\
6(1) \\
2 \\
23(2)\end{array}$ & $\begin{array}{c}4 \\
2(1) \\
12(3) \\
13(4) \\
21(7) \\
12(3) \\
8(3) \\
0 \\
72(21)\end{array}$ & $\begin{array}{l}0 \\
0 \\
1 \\
0 \\
1 \\
0 \\
2 \\
1 \\
5(0)\end{array}$ & $\begin{array}{c}6 \\
3(1) \\
15(3) \\
18(5) \\
26(7) \\
13(3) \\
16(4) \\
3 \\
100(23)\end{array}$ \\
\hline Avera & age & $\ldots$ & $48 \cdot 9$ & $43 \cdot 2$ & $51 \cdot 4$ & \\
\hline
\end{tabular}

Numbers in parentheses $=$ fatalities

TABLE 4

ESTIMATE OF INCIDENCE (INCLUdING WORKERS WHO HAD RETIRED BY THE END OF 1969)

\begin{tabular}{|c|c|c|c|c|c|c|c|c|c|c|c|}
\hline \multirow{2}{*}{\multicolumn{6}{|c|}{ No. }} & \multicolumn{2}{|c|}{$\beta$-naphthylamine } & \multicolumn{2}{|c|}{ Benzidine } & \multirow{2}{*}{\multicolumn{2}{|c|}{ Others ${ }^{1}$}} \\
\hline & & & & & & \multirow{2}{*}{\begin{tabular}{|c|} 
Production \\
219 \\
18 \\
$8 \cdot 22$ \\
\end{tabular}} & \multirow{2}{*}{$\begin{array}{r}\text { Use } \\
333 \\
5 \\
1 \cdot 5\end{array}$} & \multirow{2}{*}{$\begin{array}{c}\text { Production } \\
542 \\
61 \\
11 \cdot 25\end{array}$} & \multirow{2}{*}{$\begin{array}{c}\text { Use } \\
761 \\
11 \\
1.45\end{array}$} & & \\
\hline $\begin{array}{l}\text { Workers, includin } \\
\text { Cases } . . \\
\text { Incidence }(\%)\end{array}$ & $\begin{array}{l}\text { retir } \\
\cdots \\
\ldots\end{array}$ & $\begin{array}{l}\text { (est } \\
\cdots \\
\ldots\end{array}$ & $\begin{array}{l}\text { ted) } \\
\cdots \\
\ldots\end{array}$ & $\begin{array}{l}. \\
\cdots \\
\ldots\end{array}$ & $\begin{array}{l}\cdots \\
\cdots \\
\ldots\end{array}$ & & & & & $\begin{array}{r}669 \\
5 \\
0 \cdot 75\end{array}$ & $\begin{array}{r}2524 \\
100 \\
3.96\end{array}$ \\
\hline
\end{tabular}

${ }^{1}$ Indirect exposure, indirect work, or other amines 
TABLE 5

Number of CASES by Site OF Tumour IN THE URINARY TRACT

\begin{tabular}{|c|c|c|c|}
\hline Site & Surviving & Fatal & Total \\
\hline $\begin{array}{l}\text { Bladder } \quad . \\
\text { Bladder + ureter } \\
\text { Bladder + kidney } \\
\text { Bladder + ureter } \\
\quad \text { kidney } \quad . . \\
\text { Kidney } \quad . \\
\text { Ureter } \quad . \\
\text { Kidney + ureter }\end{array}$ & $\begin{array}{r}69 \\
0 \\
0 \\
2 \\
2 \\
1 \\
1 \\
4\end{array}$ & $\begin{array}{r}16 \\
1 \\
3 \\
1 \\
1 \\
0 \\
1\end{array}$ & $\begin{array}{r}85 \\
1 \\
3\end{array}$ \\
\hline Total & 77 & 23 & 100 \\
\hline
\end{tabular}

In Table 6, the latent period of the 100 cases in this report are classified according to the carcinogen to which they have been exposed. The overall average of the latent period was 16 years. This time span is shorter than those reported by Scott (1962) and Hueper (1969).

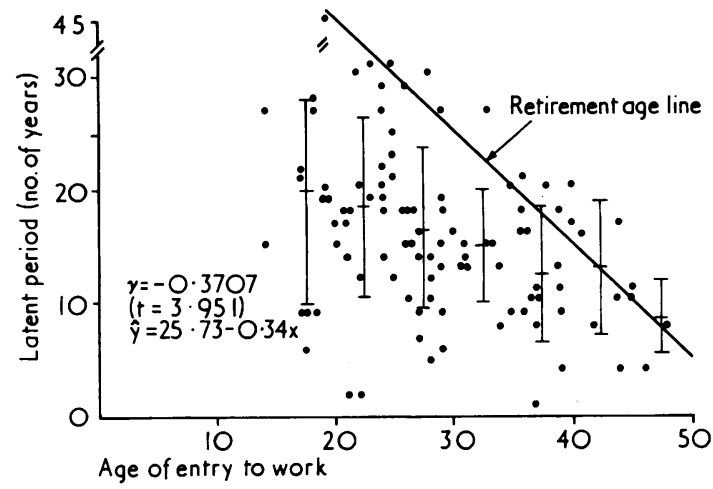

FIG. 3. Correlation between latent period and age of entry to work.
The relationship between the latent period and the time of entry into the occupation is shown in Fig. 3. The negative association between the latent period and the age of first exposure to carcinogens indicates that the older the age of entry to work, the shorter the latent period. This finding is not necessarily in agreement with previous reports (Uebelin and Pletscher, 1954; Temkin, 1963). However, the influence of the retirement age, which is 55 years in Japan, should be considered a factor in this negative association (see line showing retirement age, Fig. 3). Those people who started work at a later age are likely to have escaped observation. It is assumed, therefore, that if all the retired workers had been observed, more cases would have been detected among them. The degree of exposure in dose and time is another factor to be considered in this respect.

\section{Discussion}

From these results it is considered that the magnitude of the problem of occupational bladder tumour in the dye manufacturing industry has lessened because since 1949 many industrially developed countries have prohibited the production and use of carcinogenic aromatic amines. However, other occupations such as textile dyers, rubber workers, potters' printers, lifelong cobblers, iron and steel workers, and electric cable workers have been recognized as having a potentially significant occupational history (Veys, 1969; Davies, 1965). Furthermore, the introduction of new chemicals such as $4,4^{\prime}$-diamino diphenylmethane, o-tolidine, and o-dianisidine in clinical and biochemical laboratories may exhibit potential carcinogenic properties (Veys, 1972). Before proceeding to epidemiological studies on this new problem, we had planned to draw an overall epidemiological picture of occupational bladder tumours caused by the classical aromatic amines to which dye workers had been exposed in Japan.

TABLE 6

Distribution of Latent Period

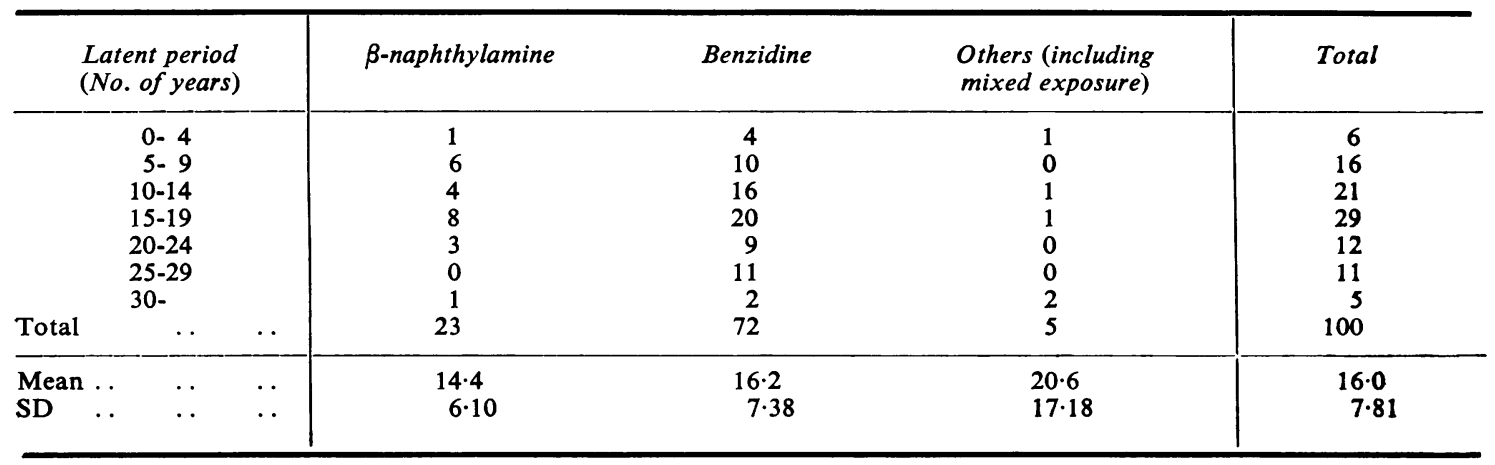


However, in spite of our efforts, the present study could not achieve a satisfactory result because we were not able to check all retired workers who had worked in the dye industry.

In particular, it is important to note here that those workers who have been exposed to $\alpha$-naphthylamine should be followed-up, since among past workers only one worker with a positive Papanicolaou test was found (Table 2). About $4 \% \beta$-naphthylamine was contained as an impurity in $\alpha$-naphthylamine in the past in Japan (Japan Dyestuff Industry Association, 1970). Since 1970 the amount of $\beta$-naphthylamine as an impurity has been reduced to less than $1 \%$. These observations, with future studies, should give important information about the dose-response relationship of the amine.

The total number of cases of occupational bladder cancer in the world since the first report was made by Rehn (1895) is estimated by Temkin (1963) to be more than 2000 and by Hueper (1969) to be between 2500 and 3000 . This occupational cancer has been reported from many countries, including the United Kingdom (Scott, 1962).

Although Hueper (1969) estimated there were 50 to 75 cases of occupational bladder cancer in Japan, our study reveals at least 100 cases and even that figure is likely to be low since our observation was limited to large dye industries and did not cover all the retired workers.

The death rate from bladder tumour is reported to be lower by two-thirds to a half in Japan than in western countries (Segi, Kunihara, and Matsuyama, 1969). There is also a report showing a lower death rate among Japanese-Americans than among Caucasian Americans (Smith, 1956). From our study, it would not appear that Japanese workers were less sensitive to bladder carcinogens compared with workers in western countries.

It is generally believed that $\beta$-naphthylamine is a stronger carcinogen than benzidine (Hueper, 1969). However, it was not possible to demonstrate this either by examining incidence or latent period in this study. The workers in many instances are exposed to both chemicals, and it is usually very difficult to find workers who are exposed only to $\beta$-naphthylamine, or only to benzidine. However, according to Case et al. (1954) there was no difference in the incidence of cancer between those exposed to $\beta$-naphthylamine and those exposed to benzidine. In addition, the important factor of dose (concentration in the air or working environment, and duration of exposure) for each worker could not be precisely determined in this study. Thus it was difficult to depict a clear-cut epidemiological picture.

In Japan, no cases were reported in the rubber industry, although the incidence of the disease in this industry seems to be high in England (Veys, 1969).
The present position of the carcinogenic aromatic amines is still complicated (Clayson and Cooper, 1970). In the light of such findings, more efforts should be made to carry out epidemiological studies and to detect cases among workers, not only in the rubber industry but in other industries and occupations where workers may be exposed to known carcinogenic amines at insidious levels, as well as to other amines which may possibly be carcinogenic.

\section{References}

Case, R. A. M., Hosker, M. E., McDonald, D. B., and Pearson, J. M. (1954). Tumour of the urinary bladder in workmen engaged in the manufacture and use of certain dyestuff intermediates in the British Chemical Industry. British Journal of Industrial Medicine, 11, 75-104.

Clayson, D. B. and Cooper, E. H. (1970). Cancer of the urinary tract. Advances in Cancer Research, 13, 271-381.

Davies, J. M. (1965). Bladder tumours in the electriccable industry. Lancet, 2, 143-146.

Hosoda, Y. (1957). Dye Chemicals (Senryo Kagaku), Gihodo, Tokyo. (In Japanese.)

Hueper, W. C. (1969). Occupational and Environmental Cancers of the Urinary System. Yale University Press, New Haven and London.

Ichikawa, T. (1958). Remote results of the bladder tumours. Japanese Journal of Urology, 49, 602-610. (In Japanese.)

Nagayo, M. and Kinoshita, R. (1940). Some significant features of cancer incidence in Japan. Yale Journal of Biology and Medicine, 12, 301-303.

Nishimura, I. (1940). On aniline tumours of the bladder (case report). Japanese Journal of Urology, 29, 733-749. (In Japanese.)

Oida, O. (1957). Studies on acute and subacute benzidine poisoning. Digest of Science and Labour, 33, 939-951. (In Japanese.)

Papanicolaou, G. N. (1947). Cytology of the urinary sediment in neoplasms of the urinary tract. Journal of Urology, 57, 375-379.

Rehn, L.(1895). Blasengeschwülste bei Fuchsin-Abreitern. Archiv der Klinischer Chirurgie, 50, 588-600.

Scott, T. S. (1962). Carcinogenic and Chronic Toxic Hazards of Aromatic Amines. Elsevier, Amsterdam.

Segi, M., Kunihara, M., and Matsuyama, T. (1969). Cancer mortality for selected sites in 24 countries. No. 5, 1964-1965. Tohoku University, School of Medicine, Sendai, Japan.

Shiki, T. (1970). A study on the occupational health of benzidine workers in connection with the incidence of neoplasm of bladder and other urinary organs. Journal of the Kurume Medical Association, 33, 363-387.

Smith, R. L. (1956). Recorded and expected mortality among the Japanese of United States and Hawaii, with special reference to cancer. Journal of the National Cancer Institute, 17, 459-473.

Takahashi, A., Komatsu, K., Koda, Y., and Toda, Hy. (1945). Statistical observation of bladder tumours in the Tokyo University Department of Urology. 
Japanese Journal of Urology, 35, 129-139. (In Japanese.)

Temkin, I. S. (1963). Industrial Bladder Carcinogens. Pergamon Press, London.

Tsuchiya, K. (1969). Epidemiological characteristics of occupational cancer in Japan. Proceedings of the XVI International Congress on Occupational Health, Tokyo, 244-246.

Tsuji, I., Kuroda, K., Nakajima, F., Fujimura, M., and Inoke, T. (1961). Mortality and clinical statistics of occupational bladder tumours in Japan. Japanese Journal of Cancer Clinics, 7, 347-355. (In Japanese.)

Uebelin, F. and Pletscher, A. (1954). Aetiologie und
Prophylare gewerblicher Tumoren in der Farbstoffindustrie. Schweizer Medizinische Wochenschrift, 84, 917-920.

Veys, C. A. (1969). Two epidemiological inquiries into the incidence of bladder tumours in industrial workers. Journal of the National Cancer Institute, 43, 219-226.

- (1972). Aromatic amines: the present status of the problem. Annals of Occupational Hygiene, 15, 11-15.

Received for publication 10 June 1974.

Accepted for publication 30 October 1974. 